\title{
Predictors of Quality of Life Among an International Sample of Mothers of Children 12 and Under With Corpus Callosum Disorders
}

\author{
Peggy Henninger, $\mathrm{PhD}$ \\ Walden University, Minneapolis, Minnesota, United States \\ (iD) https://orcid.org/0000-0001-7059-923X \\ Donna M. L. Heretick, PhD \\ Walden University, Minneapolis, Minnesota, United States \\ (iD) https://orcid.org/0000-0002-2583-3303
}

Contact: $\underline{\text { donna.heretick@mail.waldenu.edu }}$

\section{Abstract}

Previous research supports application of the double ABCX model of family adaptation of parents of children with autism spectrum disorder and other pervasive developmental disorders. This is the first study to consider processes of adaptation among parents of children with agenesis of the corpus callosum. Using a quantitative cross-sectional design, an international sample of 266 mothers of children, aged 12 or under, with agenesis of the corpus callosum completed an online survey. Parental reports of stress, resources, coping, and sense of coherence were evaluated as predictors of four subdimensions of parental quality of life for 178 mothers. In general, findings support the double ABCX model as a viable approach to understanding processes that are related to quality of life among this group of mothers.

Keywords: corpus callosum disorder; parent adaptation; mothers; double ABCX model; quantitative

Date Submitted: February 6, 2020 | Date Published: May 29, 2020

\section{Recommended Citation}

Henninger, P., \& Heretick, D. M. L. (2020). Predictors of quality of life among an international sample of mothers of children 12 and under with corpus callosum disorders. Journal of Social, Behavioral, and Health Sciences, 14, 123-137. https://doi.org/10.5590/JSBHS.2020.14.1.09

\footnotetext{
Note: Both authors contributed to the study conception and design. Material preparation, data collection, and initial analyses were performed by Peggy Henninger for her dissertation research. Reanalyses and preparation of the first draft of this manuscript were performed by Donna Heretick. Both authors commented on previous versions of the manuscript. Both authors read and approved the final manuscript. Results are based on reanalyses of data collected for the first author's dissertation research. WHOQOL-BREF scores were recalculated to produce the transformed scores that are reported in most published reports. In addition, to be consistent with publication conventions, sum scores, rather than mean scores, were reported and used for reanalyses of the other measures.
} 
Henninger \& Heretick, 2020

\section{Introduction}

When children are born with agenesis of the corpus callosum (ACC), the millions of nerve fibers in the brain's commissural pathway are partially or completely unformed (National Institutes of Health, National Institute of Neurological Disorders and Stroke [NIHNINDS], 2019). ACC is a rare, incurable disorder. Estimates of incidence rates of ACC have ranged from 1.47 per 10,00o live births (Ballardini et al., 2018) to as high as seven per 1,000 individuals (National Organization for Rare Disorders, 2019).

The corpus callosum is a structure that permits functional interaction between the hemispheres. These interactions support cognitive processes, such as executive functions, abstract reasoning, speed of processing, and problem solving. The interactions also are critical for development of social competence, emotional maturity, and communication of emotions (Paul et al., 2014). ACC may exist alone or in combination with other cerebral malformations or syndromes, cognitive impairments, developmental delays, communication disorders, and/or epileptic seizures (NIHNINDS, 2019). Children with ACC are not easily categorized, as the range of physical, social, behavioral, and cognitive outcomes vary, and there can be differing combinations of disabilities (NIHNINDS, 2019).

Similar to parents of children with other neurological developmental disorders, such as autism spectrum disorder (ASD; Pozo et al., 2014), parents of children with ACC are faced with challenges to effective coping and adaptation. As with ASD (Lau et al., 2013), children with ACC present parents with a broad variety of needs and symptoms (Margari et al., 2016), such as epilepsies and other neurological disorders (Unterberger et al., 2016), intellectual limitations (Paul et al., 2016), attention deficit disorder (El Ameen et al., 2019), limitations related to self-reference and social cognition (Anderson et al., 2017; Lombardo et al., 2012), and social and behavioral problems (Badaruddin et al., 2007).

Unlike research with parents of children with ASD (e.g., Pozo et al., 2014), to date, no research has sought to examine processes and predictors of adaptation among parents of children with ACC. Following the double ABCX model of coping (McCubbin \& Patterson, 1983), the current study fills this gap in our understanding of experiences of adaptation among parents of children with ACC.

\section{The Double ABCX Model of Family Coping and Related Research}

The double ABCX model of family coping (McCubbin \& Patterson, 1983) assumes that when parents are presented with the external stressor of a child with a disability, they may differ in their experiences of stress, perceptions of support, cognitive understanding and meaning of the situation, and coping strategies. Depending on the nature of these reactions, parents and families have better or worse adaptation and resilience to the demands with which they are faced.

\section{Experiences of Stress}

Parental stress has been defined as distress related to the role of parenting (Hayes \& Watson, 2013). External stressors that are related to a child's disability put demands on parents' physical, psychological, social, and emotional reserves. Boyd (2002) and Dardas and Ahmad (2014) found that stress among parents, especially mothers, of children with ASD was higher when their children exhibited more difficult behavior and when the parent felt less able and less competent to parent. McStay et al. (2014) noted that symptoms of externalizing behaviors, such as aggressiveness, impulsivity, and control problems, among children with ASD were the most predictive of higher parental stress and lower family quality of life (QoL). 
Henninger \& Heretick, 2020

\section{Resources}

Several types of resources have been studied to define this element of the double ABCX model among parents of children with ASD. Examples include self-reports of family cohesion, social support, and family support. McStay et al. (2014) conceptualized resources as perceived support within a family system. They found that hardiness, perceived dependability, activity and flexibility, and control over life, provided the strongest predictor of level of stress and/or family QoL for mothers and fathers.

The resources factor within the double ABCX model also is compatible with the construct of family empowerment. Family empowerment involves beliefs regarding rights, competence, motivation, and ability to reach out to obtain and use formal (e.g., agencies and professionals) and informal (e.g., friends and family) resources on behalf of their child with a disability (Koren et al., 1992; Vuorenmaa et al., 2013). Weiss et al. (2012) reported that acceptance and empowerment were statistically significant mediators between behavior problems of children with ASD and parent's mental health. Weiss et al. (2015) also found that empowerment served as a significant mediator between the level of the child's problem behaviors and the experiences of distress among a sample of mothers of children with ASD.

\section{Cognitive Appraisal}

The double ABCX model includes a factor designated as the parent's sense of coherence. This element considers types of cognitive responses that parents may employ to make sense of the situation, such as, selfblame and catastrophizing, feelings of threat, and framing the implications (positive and negative) of raising a child with a disability (McStay et al., 2014). Antonovsky (1987) developed the Sense of Coherence (SOC) Scale, which has been used in numerous studies of the double ABCX model of family adaptation. The SOC involves three dimensions: (a) comprehensibility, seeing the world as structured; (b) manageability, expecting things to be manageable; and (c) meaningfulness, seeing life as meaningful (Sivberg, 2002). For example, Pozo et al. (2013) found that higher SOC scores were associated with higher family QoL among parents of children with ASD. Using a short form of the SOC, McStay et al. (2014) also found that SOC scores were a statistically significant predictor of both stress and of family QoL among mothers and fathers of children with ASD.

\section{Coping Strategies}

The double ABCX model assumes that coping strategies add another dimension to processes defining family resilience and adaptation. The model conceptualizes coping as the family's attempts to restore balance. In general, when coping is effective, outcomes such as improved adaptation and higher QoL ensue. When coping strategies are less effective, outcomes are less positive (Fairfax et al, 2019). In fact, McCubbin and Patterson (1996) found that positive and negative coping strategies play a particularly significant role in understanding family functionality. McStay et al. (2014) evaluated coping among parents of children with ASD. They examined five dimensions of coping: acquiring social support, mobilizing to acquire and accept help, reframing, passive appraisal, and seeking spiritual support. Coping responses significantly predicted family QoL among mothers and stress among fathers of children with ASD.

Other researchers have used the Coping Health Inventory for Parents (CHIP; McCubbin et al., 1983). There are three subscales as dimensions of coping within the CHIP: (a) family integration, cooperation, and having an optimistic view of the situation, (b) maintaining social support, self-esteem, and psychological stability, and (c) understanding the health care situation through communication with other parents and health care professionals. CHIP scores generally are related to QoL among parents of children with disabilities (Fairfax et al., 2019). With respect to parents of children with ASD, effective coping is negatively related to stress (Dwirexsi et al., 2018; Kiami \& Goodgold, 2017). 


\section{Adaptation}

In the double ABCX model, adaptation may be defined through outcome variables such as QoL. In a review of the literature of studies of QoL among parents of children with ASD, Vasilopoulou and Nisbet (2016) noted inconsistent findings regarding the relationship between severity of the child's ASD (external stressor) and QoL. However, factors such as difficulties with the child's behavioral difficulties, parental unemployment, and lack of social support were predictors of lower QoL, especially among mothers.

McStay et al. (2014) specifically applied the double ABCX model to predict family QoL among parents of children with ASD. They found that externalizing behaviors by the child predicted higher maternal stress and both parents' evaluations of family QoL. Dardas and Ahmed (2015) found that two coping strategies, seeking social support and escape avoidance, among parents of children with ASD moderated the relationship between stress and QoL, while accepting responsibility served as a mediator factor.

\section{The Current Study}

The objective of the current study was to provide the first examination of experiences of parents of children with ACC. Using the double ABCX model as the theoretical framework, our specific goal was to explore the relationships of perceived stress, resources/empowerment, sense of coherence, and coping strategies to parental adaptation, here defined as QoL, among parents of children with ACC.

We predicted a negative relationship between levels of parents' stress and QoL, but positive relationships of experiences of empowerment, sense of coherence about the meaningfulness of the process of parenting, and coping with parental QoL. Although some researchers (McStay et al., 2014) have reported some differences in prediction patterns for mothers versus fathers of children with ASD, no specific hypotheses were advanced for parental differences in this study.

\section{Method}

\section{Recruitment and Sample Demographics}

Following approval by the university's institutional review board and permission of participating groups, notices about the study were posted between May and June 2018, on over 12 international Facebook group sites established as informational and support sites for professionals and families with interest in ACC. The notice was directed to parents, 18 years or older, of children who had been diagnosed with ACC and were ages 12 and under. Information contained a link to the survey site for any who were interested in participating in research to advance understanding of their experiences. When individuals went to the online survey site, they were presented with the informed consent form. Those who indicated agreement to participate then advanced to the survey materials.

The first questionnaire was demographic. Due to the overall length of the survey, only information on gender and country of origin was requested. In total, 266 eligible respondents participated in the survey. Although not by design, the full sample was composed only of mothers. The majority (66.7\%) were from the United States, and 12.4\% from Great Britain, 6.4\% from Australia, 4.5\% from Canada, 2.2\% from New Zealand, 2.7\% from other European countries, 1.8\% unknown, and 5 others (less than 1\%) from Africa, India, and Asia. 
Henninger \& Heretick, 2020

\section{Survey Measures}

\section{Brief World Health Organization Quality of Life (WHOQoL-BREF)}

The World Health Organization (WHO, 1996) developed the WHOQoL-BREF assessment to be used crossculturally to determine parental perception of their lives in four domains: physical, psychological, social relationships, and their interactions with the environment. Parents are asked to answer 26 questions while focusing on their experiences during the last two weeks. Items are presented with a 5 -point response scale $(1=$ very poor through $5=$ very good). Dardas and Ahmad (2014) reported the overall Cronbach's alpha as .93. There are four subscales for domains of QoL. Low QoL scores generally are related to higher disability severity and greater behavior problems (Markowitz et al., 2016). Following directions for scoring the QHOQoL-BREF, transformed scale scores were computed for each of the four domains. The internal reliabilities for this study's sample were physical health, $\alpha=.785$; psychological health, $\alpha=.780$; social relationships, $\alpha=.789$; and environmental health, $\alpha=.788$.

\section{Questionnaire on Resources and Stress-Short Form (QRS-SF)}

The QRS (Holroyd, 1974) was developed as a screening instrument to identify stress in families with a member who is disabled. The QRS is commonly used in published research and has good psychometric properties (Hayes \& Watson, 2013). The short form (QRS-SF) presents 66 items with true-false response options. The items assess self-reported personal problems (health, time demands, negative attitudes toward index case, overprotection/dependency, lack of social support, overcommitment/martyrdom, and pessimism), family problems (lack of family integration, family opportunity, finances), problems of index case (physical incapacitation, lack of activities, occupational limitations, social obtrusiveness, difficult personality, personality characteristics). Internal reliability has been estimated at $\alpha=.93$ (Saloviita et al., 2003). The Kuder-Richardson-20 coefficient (equivalent to Cronbach's alpha) was used to evaluate internal consistency among the scale's dichotomous items. The resulting value was $\alpha=.85$ for the mothers in this sample. Responses of true were coded as 1 and responses of false were coded as 0 . The sum of the items was used for the overall scale score.

\section{The Coping Health Inventory for Parents (CHIP)}

The CHIP was developed by McCubbin et al. (1996). The 45-item parent questionnaire assesses parents' perceptions of how they manage family life with a child with a chronic illness. Items evaluate optimistic family definition of the situation, family stability, and understanding of situations with medical staff and other parents. Items are presented with a 4-point Likert scale: $0=$ not helpful, $1=$ minimally helpful, $2=$ moderately helpful, $3=$ extremely helpful. Test-retest reliability has been reported as ranging from .68 to .86 and Cronbach's alpha for all items ranged from .90 to .86 (Aguilar-Vafaie, 2008). Internal reliability for the current sample was .818 . The score was the sum of the items' ratings.

\section{The Family Empowerment Scale (FES)}

Koren et al. (1992) developed the FES to measure three factors reflecting different areas of a family's life where they are empowered or need support on behalf of a child/family member with special needs: feeling empowered in their own home, able to get what they need from the service systems available, and the ability to maneuver and acquire their community needs. There are 34 statements and a 5-point response scale for each statement: 1 = never, $2=$ seldom, $3=$ sometimes, $4=$ often, and $5=$ very often. Cronbach's alphas have ranged from .867 to .895 for the five subscales (Kageyama et al., 2016) and .84 to .90 for all items (Vuorenmaa et al., 2013). Concurrent validity has been reported for families who participated in service activities in school settings (Vuorenmaa et al., 2013). Overall internal reliability for the current study was $\alpha=$ .818 . The score was the total of the ratings. 


\section{Antonovsky's Sense of Coherence Scale-Short Form (SOC-13)}

The SOC was developed to assess perceived comprehensibility, manageability, and meaningfulness of one's life. The short form includes 13 statements, each presented with a 7-point response scale, with response items related to the nature of the question (e.g., $1=$ no clear goal or purpose at all to $7=$ very clear goals and purpose). The SOC-13 has good test-retest reliability (e.g., $r=.54$ over a 2-year interval), internal reliability (Cronbach's alphas range from .74 to .91 for total score), and construct validity (Antonovsky, 1993). Overall internal reliability for the current sample was .822. Scores were the total of ratings.

\section{Results}

Data were analyzed using SPSS (Version 25). Descriptive statistics for total scale scores for the current study are summarized in Table 1.

\section{Hypothesis Testing}

Our goal was to examine adaptation (QoL) among parents of children diagnosed with ACC by applying the double ABCX model, which posits predictive factors of parental stress, coping, resources, and sense of coherence. We hypothesized a negative relationship between levels of a parent's stress and QoL, but positive relationships for experiences of empowerment, sense of coherence about the meaningfulness of the process of parenting, and coping with parental QoL, and that the overall model would predict a significant amount of the variance in QoL.

After assessing data for compliance with assumptions, we computed bivariate correlations between predictors and with scores on each of the dimensions of QoL. The correlations, which are summarized in Table 2, initially suggested that, except for reported levels of parental stress, individual factors in the double ABCX model were related to each of the various dimensions of QoL. 
Table 1. Sample Means and Comparison of Current Scores for Mothers of Children With Agenesis of the Corpus Callosum (ACC) With Scores Previously Reported for Mothers of Children With Autism Spectrum Disorder (ASD) and Other Disabilities

\begin{tabular}{|c|c|c|c|c|c|c|c|}
\hline Variable measure & Study & $\begin{array}{l}\text { Children's } \\
\text { condition }\end{array}$ & $N$ & $M$ & $S D$ & $t$ & $\boldsymbol{p}$ \\
\hline \multirow{4}{*}{$\begin{array}{l}\text { Questionnaire on } \\
\text { Resources and Stress- } \\
\text { Short Form }\end{array}$} & Current & $\mathrm{ACC}$ & 266 & 37.00 & 5.26 & & \\
\hline & Bouma and & ASD & 24 & 29.08 & $7 \cdot 30$ & 6.82 & $<.0001$ \\
\hline & Schweitzer (1990) & Controla & 24 & 13.17 & 5.10 & 21.31 & $<.0001$ \\
\hline & Riley (2016) & ASD & 22 & 34.00 & 11.60 & 2.27 & .024 \\
\hline \multirow{5}{*}{$\begin{array}{l}\text { Sense of Coherence } \\
\text { Scale-Short Form }\end{array}$} & Current & $\mathrm{ACC}$ & 266 & 55.07 & 26.03 & & \\
\hline & Olsson and & ASD & 62 & 59.50 & 14.40 & -1.29 & n.s. \\
\hline & Hwang (2000) & Intellectual & & & & & \\
\hline & & disability & 144 & 64.40 & 14.50 & -3.98 & $<.0001$ \\
\hline & & Controla $^{\mathrm{a}}$ & 202 & 69.10 & 11.90 & -7.12 & $<.0001$ \\
\hline \multirow{2}{*}{$\begin{array}{l}\text { Coping Health } \\
\text { Inventory for Parents }\end{array}$} & Current & $\mathrm{ACC}$ & 266 & 94.18 & 20.71 & & \\
\hline & Hall and Graff (2011) & ASD & 50 & 94.12 & 16.05 & .02 & n.s. \\
\hline \multirow{2}{*}{$\begin{array}{l}\text { Family Empowerment } \\
\text { Scale }\end{array}$} & Current & $\mathrm{ACC}$ & 178 & 188.74 & 31.03 & & \\
\hline & Taylor et al. (2017) & ASD & 41 & 122.30 & 19.81 & 5.07 & n.s. \\
\hline \multicolumn{8}{|l|}{$\begin{array}{l}\text { Brief World Health } \\
\text { Organization Quality } \\
\text { of Life }\end{array}$} \\
\hline \multirow[t]{5}{*}{ Physical } & Current & $\mathrm{ACC}$ & 265 & 70.03 & 20.29 & & \\
\hline & Dardas and Ahmad (2014) & ASD & 144 & 64.81 & 13.85 & 2.75 & .0061 \\
\hline & Malhotra et al. (2012) & ASD & 40 & 46.40 & 15.85 & 7.05 & $<.0001$ \\
\hline & & MR & 40 & 46.67 & 12.44 & 7.08 & $<.0001$ \\
\hline & & Control $^{\mathrm{a}}$ & 40 & $59 \cdot 35$ & 14.40 & 3.21 & .0015 \\
\hline \multirow[t]{5}{*}{ Psychological } & Current & $\mathrm{ACC}$ & 265 & 63.80 & 20.95 & & \\
\hline & Dardas and Ahmad (2014) & ASD & 144 & 59.68 & 16.01 & 2.06 & .0404 \\
\hline & Malhotra et al. (2012) & Autism & 40 & 40.53 & 12.96 & 6.85 & $<.0001$ \\
\hline & & MR & 40 & 35.05 & 9.41 & 8.54 & $<.0001$ \\
\hline & & Controla $^{\mathrm{a}}$ & 40 & $55 \cdot 35$ & 14.48 & 2.46 & .0144 \\
\hline \multirow[t]{5}{*}{ Social } & Current & $\mathrm{ACC}$ & 265 & 63.26 & 27.20 & & \\
\hline & Dardas and Ahmad (2014) & ASD & 144 & 64.27 & 17.34 & -.40 & n.s. \\
\hline & Malhotra et al. (2012) & Autism & 40 & 46.25 & 13.61 & 3.88 & .0001 \\
\hline & & MR & 40 & 38.12 & 20.06 & 5.62 & $<.0001$ \\
\hline & & Controla & 40 & 62.80 & 16.91 & .10 & n.s. \\
\hline \multirow[t]{5}{*}{ Environmental } & Current & $\mathrm{ACC}$ & 265 & 74.66 & 17.80 & & \\
\hline & Dardas and Ahmad (2014) & ASD & 144 & 55.79 & 14.21 & 10.96 & $<.0001$ \\
\hline & Malhotra et al. (2012) & ASD & 40 & 49.10 & 17.14 & 8.51 & $<.0001$ \\
\hline & & MR & 40 & 42.42 & 18.97 & 10.59 & $<.0001$ \\
\hline & & Controla & 40 & 59.40 & 10.64 & 5.28 & $<.0001$ \\
\hline
\end{tabular}

Note. $\mathrm{MR}=$ mental retardation .

a Typically developing children. 
Table 2. Bivariate Correlations Between Total Scores on Each Double ABCX Model Predictor Variable and the Quality of Life Subscale Scores for Adaptation

\begin{tabular}{lcccc}
\hline & \multicolumn{4}{c}{ Predictors } \\
\cline { 2 - 4 } Measure & QRS-SF & CHIP & FES & SOC-13 \\
\hline WHOQOL-BREF & & & \\
Physical health & $-.16^{* *}$ & $.38^{* * *}$ & $.29^{* * *}$ & $.46^{* * *}$ \\
Psychological & -.04 & $.44^{* * *}$ & $.58^{* * *}$ & $.38^{* * *}$ \\
$\quad$ health & & $.43^{* * *}$ & $.44^{* * *}$ & $.42^{* * *}$ \\
$\quad$ Social & -.06 & $.33^{* * *}$ & $.38^{* * *}$ & $.41^{* * *}$ \\
$\quad$ relationships & -.07 & $-.32^{* * *}$ & -.09 & -.04 \\
Environment & - & - & $.67^{* * *}$ & .17 \\
QRS-SF & & & - & .04 \\
CHIP & & & - \\
FES & & & \\
SOC-13 & & &
\end{tabular}

Note. QRS-SF = Questionnaire on Resources and Stress-Short Form $(N=265)$; CHIP $=$ Coping Health Inventory for Parents $(N=265)$; FES = Family Empowerment Scale $(N=177)$; SOC-13 = Sense of Coherence Scale-Short Form $(N=$ 264); WHOQOL-BREF = brief World Health Organization Quality of Life.

${ }^{* * *} p<.01 .{ }^{* * *} p<.001$ (two-tailed significance).

Multiple linear regressions were used to evaluate the double ABCX model as a predictor of each of the four subdimensions of QoL. The sample size for the regressions was reduced to 178 due to missing survey responses for a number of participants for items on the FES scale. Assumptions were met and VIF values for the predictors were $<10$ for each of the regressions. Table 3 presents a summary of results for the multiple regression analyses. There was support of the double ABCX model as an overall predictor of each of the subdimensions of QOL. The highest proportion of variance was predicted for QoL related to the mother's psychological health, while lowest proportion was predicted for QoL related to physical health.

When controlling for the other predictors, coping was a significant predictor of three of the four dimensions of QoL and showed a trend $(p=.07)$ for predicting environmental health. Empowerment significantly predicted all but physical health QoL scores. Stress predicted psychological and social dimensions of QoL, and sense of coherence significantly predicted psychological and environmental health QoL. 
Table 3. Results of Multiple Linear Regressions to Assess the Double ABCX Model of Predictors of Quality of Life (QoL) Among Parents of Children With Agenesis of the Corpus

\begin{tabular}{|c|c|c|c|c|c|c|}
\hline QoL dimension & Predictor & Adjusted $R^{2}$ & Overall Fa & $\beta$ & $t$ & $\boldsymbol{p}$ \\
\hline \multirow[t]{5}{*}{ Physical health } & Full model & .149 & 8.73 & & & $<.001$ \\
\hline & Stress & & & .057 & .74 & n.s. \\
\hline & Coping & & & .441 & 4.19 & $<.001$ \\
\hline & Empowerment & & & .085 & .84 & n.s. \\
\hline & Sense of coherence & & & .147 & 1.56 & n.s. \\
\hline \multirow[t]{5}{*}{ Psychological } & Full model & .384 & 23.39 & & & $<.001$ \\
\hline & Stress & & & .185 & 2.79 & .006 \\
\hline & Coping & & & .252 & 2.81 & .006 \\
\hline & Empowerment & & & .532 & 6.17 & $<.001$ \\
\hline & Sense of coherence & & & .177 & 2.19 & .030 \\
\hline \multirow[t]{5}{*}{ Social relations } & Full model & .241 & 14.98 & & & $<.001$ \\
\hline & Stress & & & .151 & 2.05 & .042 \\
\hline & Coping & & & .355 & 3.57 & $<.001$ \\
\hline & Empowerment & & & .297 & 3.10 & .002 \\
\hline & Sense of coherence & & & .134 & 1.50 & n.s. \\
\hline \multirow[t]{5}{*}{ Environmental } & Full model & .173 & 10.23 & & & $<.001$ \\
\hline & Stress & & & .052 & .68 & n.s. \\
\hline & Coping & & & .191 & 1.84 & $(.07)$ \\
\hline & Empowerment & & & .412 & 4.12 & $<.001$ \\
\hline & Sense of coherence & & & .265 & 2.83 & .005 \\
\hline
\end{tabular}

${ }^{\mathrm{a}} d f=4,172$.

\section{Discussion}

Although considerable attention has been given to experiences and adjustment among parents of children with autism and other types of developmental disabilities, this is the first study to consider challenges and processes of adaptation among parents of children with ACC. We surveyed an international sample of mothers of children with ACC who were active on various online support and information networks. The theoretical framework and methods we selected drew directly from previous work to explore adaptation among parents of children with ASD and similar disorders. In general, findings support the hypotheses for this study that were based on application of the double ABCX model of parental adaptation to understand processes that are related to QoL among this group of mothers. Experiences of parental stress, resources, sense of coherence, and coping strategies were significant predictors of overall QoL as an indicator of parent adaptation. Further, there were observations of differences in the strength of prediction for different dimensions of QoL: overall, the double ABCX model was strongest for predicting psychological QoL, followed by social QoL, environmental QoL, and lowest for physical health QoL.

\section{Comparing Mothers of Children With ACC With Other Groups}

Although direct comparisons within a single study await future research, there are some early, and limited, indications of how mothers of children with ACC may compare with mothers of children with other developmental disabilities. Table 1 contains a sample of mean scores on the same scales that have been reported elsewhere for mothers of children with ASD or other developmental disorders, as well as for 
comparison groups of mothers of typically developing children. As may be noted, our mothers' stress scores (QRS-SF) were significantly higher than those reported for mothers of children with ASD or typically developing children (Bouma \& Schweitzer, 1990; $p<.0001$; Riley, 2016, $p=.24$ ). SOC-13 scores for sense of coherence among our mothers of children with ACC were significantly lower than those reported by Olsson and Hwang (2000) for samples of mothers of children with autism, intellectual disabilities, or typical development $(p<.0001)$. However, our mothers of children with ACC were similar to mothers of children with ASD on both CHIP scores for coping (Hall \& Graff, 2011) and FES scores for resources/empowerment. By contrast, with respect to the QoL measure, scores on subscales of the WHOQoL-BREF for our mothers of children with ACC tended to be higher, that is more positive, than those reported for mothers in other samples with children with autism disorder, MRR, or typical development (Dardas \& Ahmad, 2014; Malhotra et al., 2012). Of course, future research is needed to provide direct comparisons of parents of children with ACC with other parent groups.

\section{Limitations}

There are several limitations to this first exploration of adaptation among parents of children with ACC. First, it was an online survey, with typical advantages and disadvantages (Nayak \& Narayan, 2019). As a plus, this design allowed for collecting data from an international sample and assured anonymity and confidentiality. However, it is difficult to know the actual response rate without knowing how many of the groups' members visited the sites and saw the posting for the study. Further, the sample was nonprobabilistic: self-selection of participants, as well as sample size, limit generalization of these results. In addition, it was a cross-sectional design, exploring self-reports at one point in time. It may be that there are critical aspects of changes both in the child's symptoms and their severity, as well as the parents' status, that are not appreciated using crosssectional designs. Also, we did not collect sufficient demographic information to appreciate other factors, such as age of child, formal diagnosis status, severity of child's symptoms, socioeconomic status, education level, marital status, that may have been specific to these mothers.

In hindsight, the FES may not be an ideal instrument to use with this population. There were missing responses by a number of respondents, which led to a listwise $N$ of 178 . Perhaps some of these items were not relevant for some of the respondents. Fatigue does not seem to explain these missing responses as the FES was completed as the next to the last survey in the package and the same respondents completed all the other survey instruments.

Finally, although each full model explained a statistically significant proportion of the variance in each the QoL subscale scores ( $p$.001), adjusted $R^{2}$ values only ranged from .149 to .384 , indicating small to, at best, moderate effect sizes.

\section{Recommendations for Future Research}

\section{Expanding consideration of demographics and other factors}

As the first study with mothers of children with ACC, there is much room for ongoing research in this area. Future research should employ a broader sampling of parents from more populations and situations, including parents at various stages of experience with parenting children with ACC. In addition, information regarding respondent demographics, as well as parenting demands, child's symptoms, and other environmental factors (e.g., Miranda et al., 2019, with mothers of children with autism), certainly could expand the understanding of stress and adaptation among parents of children with ACC.

\section{Reexamining relationships between stress, other predictors, and QoL}

There are some questions about the relationship of stress to other predictors, which may be an artifact of our sampling or measure. We found that our mothers' self-reported stress was not related significantly to most of the other elements of the double ABCX model of functioning or adaptation. Stress was inversely associated 
with coping responses and with only one dimension, physical health, of QoL. Notably, parental stress was not related to sense of coherence. This result is inconsistent with assumptions, such as those from the Lazarus and Folkman (1984) theory of stress, that experiences of stress are associated with cognitive appraisal of the event and coping responses. Further, stress usually has been related to lower sense of coherence among parents of children with ASD (Batool \& Khurshid, 2015; Golfenshtein et al., 2016). Was this finding a function of the higher stress levels reported by our mothers of children with ACC, as compared with those reported for mothers of children with ASD? Was this outcome an artifact of the measure we used, the QRS-SF, to assess parental stress? We could not locate another published study that used both the QRS-SF and SOC to evaluate this relationship among parents of children with disabilities. The answer will await further research with parents of children with ACC.

\section{Practical Significance}

This is the first study to explore adaptation among parents of children with ACC. Continuing focus on the needs and functioning of this group of parents may enlighten both the parents and those who may be able to offer effective support. For example, results highlight the importance of considering mothers' experiences of empowerment in relation to the psychological, social, and environmental elements of their QoL.

Empowerment, as defined in this study, is related to three factors: feeling empowered in their own home, ability to get what they need from the service systems available, and the ability to maneuver and acquire their community needs (Koren et al., 1992). There is background knowledge and experiences for supporting empowerment for parents of children with ASD (Webster et al., 2017). For example, providing familycentered care and parent-professional partnerships (Casagrande \& Ingersoll, 2017), family-focused psychoeducational therapy (Zhou et al., 2019), and family peer advocates (Jamison et al., 2017) may be applicable to improve empowerment among parents of children with ACC.

Further, exploring parents of children with ACC through the lens of the double ABCX model of family adaptation may be useful for conceptualizing and responding to family needs and in planning interventions. Pickard and Ingersoll (2017) have argued that the double ABCX model should be used as a family-focused service delivery model for families of children with ASD. Xu (2007) reported an actual application of the double ABCX model for two culturally diverse families with young children with disabilities. Xu described a process that may be used by professionals: Step 1: observe and identify the primary stressor and others that accumulate along with it; Step 2: identify existing resources the family has used to cope, and those that are still needed, and work with the family's own situation (e.g., attitudes, accessibility), to develop plans and strategies for obtaining more resources; Step 3: examine and re-examine family perceptions across the process, recognizing that "perceptions are dynamic, especially where multiple variables are involved" (p. 436); Step 4: empower families with effective coping strategies. Thus, continued research, and its application for enhancing adaptation among parents of children with ACC, is warranted.

\section{References}

Aguilar-Vafaie, M. E. (2008). Coping-health inventory for parents: Assessing coping among Iranian parents in the care of children with cancer and introductory development of an adapted Iranian coping-health inventory for parents. Children's Health Care, 37, 237-260. https://doi.org/10.1080/02739610802437202

Anderson, L. B., Paul, L. K., \& Brown, W. S. (2017). Emotional intelligence in agenesis of the corpus callosum. Archives of Clinical Neuropsychology, 32(3), 267-279. https://doi.org/10.1093/arclin/acxo01

Antonovsky, A. (1987). Sense of coherence-orientation to life questionnaire. Jossey-Bass. 
Henninger \& Heretick, 2020

Antonovsky, A. (1993). The structure and properties of the sense of coherence scale. Social Science and Medicine, 36(6), 725-733. https://doi.org/10.1016/0277-9536(93)90033-Z

Badaruddin D. H., Andrews, G. L., Bölte, S., Schilmoeller, K. J., Schilmoeller, G., Paul, L. K., et al. (2007). Social and behavioral problems of children with agenesis of the corpus callosum. Child Psychiatry and Human Development, 38, 287-302. https://doi.org/10.1007/s10578-007-0065-6

Ballardini, E., Marino, P., Maletti, E., Astolfi, G., \& Neville, A. J. (2018). Prevalence and associated factors for agenesis of corpus callosum in Emilia Romagna (1981-2015). European Journal of Medical Genetics, 61(9), 524-530. https://doi.org/10.1016/j.ejmg.2018.06.004

Batool, S. S., \& Khurshid, S. (2015). Factors associated with stress among parents of children with autism Journal of the College of Physicians and Surgeons Pakistan, 25(10), 752-756. https://doi.org/10.2015/JCPSP.752756

Bouma, R., \& Schweitzer, R. (1990). The impact of chronic childhood illness on family stress: A comparison between autism and cystic fibrosis. Journal of Clinical Psychology, 46(6), 722-730. https://doi.org/10.1002/1097-4679(199011)46:6<722::AID-JCLP2270460605>3.0.CO;2-6

Boyd, B. (2002). Examining the relationship between stress and lack of social support in mothers of children with autism. Focus on Autism and Other Developmental Disabilities, 17(4), 207-215. https://doi.org/10.1177/10883576020170040301

Casagrande, K. A., \& Ingersoll, B.R. (2017). Service delivery outcomes in ASD: Role of parent education, empowerment, and professional partnerships. Journal of Child and Family Studies, 26, 2386-2395. https://doi.org/10.1007/s10826-017-0759-8

Dardas, L. A., \& Ahmad, M. M. (2014). Quality of life among parents of children with autistic disorder: A sample from the Arab world. Research in Developmental Disabilities, 35, 278-287. https://doi.org/10.1016/j.ridd.2013.10.029

Dardas, L. A., \& Ahmad, M. M. (2015). Coping strategies as mediators and moderators between stress and quality of life among parents of children with autistic disorder. Stress and Health, 31(1), 5-12. https://doi.org/10.1002/smi.2513

Dwirexsi, W., Lukman, M., \& Rafiyah, I. (2018). The correlation between coping strategy and stress of parents who have children with autism. Journal of Nursing Care, 1(3), 172-179. https://doi.org/10.24198/jnc.v1i3.17861

El Ameen, N., Ibrahim, M. A., \& Mouner, S. M. (2019). MRI evaluation of the brain in children with attention deficit and hyperactivity disorder: How to hear the whispers early? International Journal of Pediatrics, 7(5), 9379-9390. https://doi.org/10.22038/ijp.2019.37060.3228

Fairfax, A., Brehaut, J., Colman, I., Sikora, L., Kazakova, A., Chakraborty, P., \& Potter, B. K. (2019). A systematic review of the association between coping strategies and quality of life among caregivers of children with chronic illness and/or disability. BMC Pediatrics, 19(1), 215. https://bmcpediatr.biomedcentral.com/articles/10.1186/s12887-019-1587-3

Golfenshtein, N., Srulovici, E., \& Medoff-Cooper, B. (2016). Investigating parenting stress across pediatric health conditions-a systematic review. Comprehensive Child and Adolescent Nursing, 39(1), 41-79. https://doi.org/10.1177/1074840716676083

Hall, H. R., \& Graff, J. C. (2011). The relationships among adaptive behaviors of children with autism, family support, parenting stress, and coping. Issues in comprehensive Pediatric Nursing, 34(1), 4-25. https://doi.org/10.3109/01460862.2011.555270

Hayes, S. A., \& Watson, S. L. (2013). The impact of parenting stress: A meta-analysis of studies comparing the experience of parenting stress in parents of children with and without autism spectrum disorder. 
Journal of Autism and Developmental Disorders, 43, 629-642. https://doi.org/10.1007/s10803012-1604-y

Holroyd, J. (1974). The questionnaire on resources and stress: An instrument to measure family response to a handicapped family member. Journal of Community Psychology, 2, 92-94. https://psycnet.apa.org/doi/10.1002/1520-6629(197401)2:1\%3C92::AIDJCOP2290020133\%3E3.0.CO;2-A

Jamison, J. M., Fourie, E., Siper, P. M., Trelles, M. P., George-Jones, J., Buxbaum, Grice A., Kata, J., Holl, E., Shaoul, J., Hernandez, B., Mitchell, L, McKay, M. M., Buxbaum, J. D., \& Kolevzon, A. (2017). Examining the efficacy of a family peer advocate model for Black and Hispanic caregivers of children with autism spectrum disorder. Journal of Autism and Developmental Disorders, 47, 13141322. https://doi.org/10.1007/s10803-017-3045-O

Kageyama, M., Nakamura, Y., Kobayashi, S., \& Yokoyama, K. (2016). Validity and reliability of the family empowerment scale for caregivers of adults with mental health issues. Journal of Psychiatric and Mental Health Nursing, 23, 521-531. https://doi.org/10.1111/jpm.12333

Kiami, S. R., \& Goodgold, S. (2017). Support needs and coping strategies as predictors of stress level among mothers of children with autism spectrum disorder. Autism Research and Treatment, 8685950. https://doi.org/10.1155/2017/8685950

Koren, P. E., DeChillo, N., \& Friesen, B. J. (1992). Measuring empowerment in families whose children have emotional disabilities: A brief questionnaire. Rehabilitation Psychology, 37(4), 305-321.

Lau, Y. C., Hinkley, L. B., Bukshpun, P., Strominger, Z. A., Wakahiro, M. L., Baron-Cohen, S., Allison, C., Auyeung, B., Jeremy, R. J., Nagarajan, S. S., Sherr, E. H., \& Marco, E. J. (2013). Autism traits in individuals with agenesis of the corpus callosum. Journal of Autism and Developmental Disorders, 43, 1106-1118. https://doi.org/10.1007/s10803-012-1653-2

Lazarus, R. S., \& Folkman, S. (1984). Stress, appraisal, and coping. Springer.

Lombardo, M. V., Chakrabarti, B., Lai, M. C., MRC AIMS Consortium, \& Baron-Cohen, S. (2012). Selfreferential and social cognition in the case of autism and agenesis of the corpus callosum. Molecular Autism, 3, 14. https://doi.org/10.1186/2040-2392-3-14

Malhotra, S., Khan, W., \& Bhatia, M. S. (2012). Quality of life of parents having children with developmental disabilities. Delhi Psychiatry Journal, 15(1), 173-174. https://doi.org/10.1016/S1569-1861(09)70019-1

Margari, L., Palumbi, R., Campa, M. G., Operto, F. F., Buttiglione, M., Craig, F., Matricardi, S., \& Verrotti, A. (2016). Clinical manifestations in children and adolescents with corpus callosum abnormalities. Journal of Neurology, 263, 1939-1945. https://doi.org/10.1007/s00415-016-8225-x

Markowitz, L. A., Reyes, C., Embacher, R. A., Speer, L. L., Roizen, N., \& Frazier, T. W. (2016). Development and psychometric evaluation of a psychosocial quality of life questionnaire for individuals with autism and related developmental disorders. Autism, 2O(7), 832-844. https://doi.org/10.1177/1362361315611382

McCubbin, H. I., McCubbin, M. A., Nevin, R., \& Cauble, A. E. (1996). Coping-Health Inventory for Parents (CHIP). In H. I. McCubbin, A. I. Thompson, \& M. A. McCubbin (Eds.), Family assessment: Resiliency, coping, and adaptation-inventories for research and practice (pp. 407-454). University of Wisconsin System.

McCubbin, H. I., \& Patterson, J. M. (1983). The family stress process: The ABCx model of adjustment and adaptation. In H. I. McCubbin, M. Sussman, \& J. Patterson (Eds.), Social stress and the family: Advances and developments in family stress theory and research (pp. 7-38). Haworth. 
McStay, R. L., Trembath, D., \& Dissanayake, C. (2014). Stress and family quality of life in parents of children with autism spectrum disorder: Parent gender and the double ABCX model. Journal of Autism and Developmental Disorders, 44(12), 3101-3118. https://doi.org/10.1007/s10803-014-2178-7

Miranda, A., Mira, A., Berenguer, C., Rosello, B., \& Baixauli, I. (2019). Parenting stress in mothers of children with autism without intellectual disability: Mediation of behavioral problems and coping strategies. Frontiers in Psychology, 10, 464. https://doi.org/10.3389/fpsyg.2019.00464

National Institutes of Health, National Institute of Neurological Disorders and Stroke (NIHNINDS). (2019). Agenesis of the corpus callosum information page. https://www.ninds.nih.gov/Disorders/AllDisorders/Agenesis-Corpus-Callosum-Information-Page

National Organization for Rare Diseases. (2019). Agenesis of corpus callosum. https://rarediseases.org/rarediseases/agenesis-of-corpus-callosum/

Nayak, M. S. D. P., \& Narayan, K. A. (2019). Strengths and weakness of online surveys. IOSR Journal of Humanities and Social Science, 24(5), 31-38. https://doi.org/10.9790/0837-2405053138

Olsson, M. B., \& Hwang, C. P. (2002). Sense of coherence in parents of children with different developmental disabilities. Journal of Intellectual Disability Research, 46(7), 548-559. https://doi.org/10.1046/j.1365-2788.2002.00414.x

Paul, L. K., Corsello, C., Kennedy, D. P., \& Adolphs, R. (2014). Agenesis of the corpus callosum and autism: A comprehensive comparison. Brain, 137, 1813-1829. https://doi.org/10.1093/brain/awuo70

Paul, L. K., Erickson, R. L., Hartman, J. A., \& Brown, W. S. (2016). Learning and memory in individuals with agenesis of the corpus callosum. Neuropsychologia, 86, 183-192.

https://doi.org/10.1016/j.neuropsychologia.2016.04.013

Pickard, K. E., \& Ingersoll, B. R. (2017). Using the double ABCX model to integrate services for families of children with ASD. Journal of Child and Family Studies, 26(3), 810-823. https://doi.org/10.1007/s10826-016-0605-4

Pozo, P., Sarriå, E., \& Brioso, A. (2014). Family quality of life and psychological well-being in parents of children with autism spectrum disorders: A double ABCX model. Journal of Intellectual Disability Research, 58(5), 442-458. https://doi.org/10.1111/jir.12042

Riley, R. M. (2016). Cognitive functioning as a moderator in the relation between externalizing behavior problems in children with autism spectrum disorder and stress among their parents (Honors thesis). University of Southern Mississippi.

https://aquila.usm.edu/cgi/viewcontent.cgi?article=1405\&context=honors theses

Saloviita, T., Italinna, M., \& Leinonen, R. (2003). Explaining the parental stress of fathers and mothers caring for a child with an intellectual disability: A double ABCX model. Journal of Intellectual Disability Research, 47(4-5), 300-312. https://doi.org/10.1046/j.1365-2788.2003.00492.x

Sivberg, B. (2002). Family system and coping behaviors. Autism, 6(4), 397-409. https://doi.org/10.1177/1362361302006004006

Taylor, J. L., Hodapp, R. M., Burke, M. M., Waitz-Kudla, S. N., \& Rabideau, C. (2017). Training parents of youth with autism spectrum disorder to advocate for adult disability services: Results from a pilot randomized controlled trial. Journal of Autism and Developmental Disorders, 47(3), 846-857. https://doi-org/10.1007/s10803-016-2994-Z

Unterberger, I., Bauer, R., Walser, G., \& Bauer, G. (2016). Corpus callosum and epilepsies. Seizure, 37, 66-60. https://doi.org/10.1016/j.seizure.2016.02.012 
Vasilopoulou, E., \& Nisbet, J. (2016). The quality of life of parents of children with autism spectrum disorder: A systematic review. Research in Autism Spectrum Disorders, 23, 36-49. http://faratarjome.ir/u/media/shopping files/store-EN-1483168696-3165.pdf

Vuorenmaa, M., Halme, N., Astedt-Kurki, P., Kaunonen, M., \& Perala, M. L. (2013). The validity and reliability of the Finnish family empowerment scale (FES): A survey of parents with small children. Child: Care, Health, and Development, 4O(4), 597-606. https://doi.org/10.1111/cch.12081

Webster, A., Cumming, J., \& Rowland, S. (Eds.). (2017). Empowering parents of children with autism spectrum disorder: Critical decision-making for quality outcomes. Springer

Weiss, J. A., Cappadocia, M. C., MacMullin, J. A., Viecili, M., \& Lunsky, Y. (2012). The impact of child problem behaviors of children with ASD on parent mental health: The mediating role of acceptance and empowerment Autism, 16(3), 261-274. https://doi.org/10.1177/1362361311422708

Weiss, J. A., MacMullin, J. A., \& Lunsky, Y. (2015). Empowerment and parent gain as mediators and moderators of distress in mothers of children with autism spectrum disorders. Journal of Child and Family Studies, 24(7), 2038-2045. https://doi.org/10.1007/s10826-014-0004-7

World Health Organization (WHO). (1996). Quality of Life (WHOQOL) brief questionnaire, field trial version.

$\mathrm{Xu}, \mathrm{Y}$. (2007). Empowering culturally diverse families of young children with disabilities: The double ABCX model. Early Childhood Education Journal, 34(6), 431-437. https:://doi.org/10.1007/s10643-0060149-0

Zhou, Y., Yin, H., Wang, M., \& Wang, J. (2019). The effect of family-focused psychoeducational therapy for autism spectrum disorder children's parents on parenting self-efficacy and emotion. Archives of psychiatric nursing, 33(1), 17-22. https://doi.org/10.1016/j.apnu.2018.08.002

$\underline{\Delta} \mid \mathrm{JSBHS}$

The Journal of Social, Behavioral, and Health Sciences (JSBHS), co-sponsored by the College of Health Sciences and the College of Social and Behavioral Sciences at Walden University, is a peer-reviewed, online, interdisciplinary journal focusing on theoretically-based research that addresses contemporary national and international issues. JSBHS articles include peer-reviewed research reports, brief resports, comprehensive literature reviews, books reviews, and student research. 